\title{
Nonagésimo aniversario de la Sociedad Mexicana de Pediatría: 1930-2020
}

\author{
Ninetieth anniversary of the Mexican Society of Pediatrics: 1930-2020 \\ Carlos García-Bolaños*,+ \\ * Presidente de la Sociedad Mexicana de Pediatría, 2019-2020.
}

\section{UNA SOCIEDAD FIEL A SUS VALORES}

La Sociedad Mexicana de Pediatría (SMP) fue fundada en 1930, en la Ciudad de México. Fue aquí, en la principal ciudad de nuestro país, donde el Dr. Mario A. Torroella creó la primera agrupación pediátrica organizada de México. Desde su fundación, la Sociedad ya enarbolaba los valores que siguen siendo su emblema principal. A lo largo de los 90 años de su existencia, la SMP se ha distinguido por el ingenio, funcionalidad, confiabilidad y la calidad de los programas académicos. Todo lo cual ha sido de las preocupaciones primordiales de cada uno de los distinguidos expresidentes durante estos primeros 90 años. Al mantener estos valores y objetivos, ha llevado a consolidar el respeto que la Sociedad tiene por los pediatras mexicanos (y de otras latitudes) en la actualidad.

Nueve décadas después de haber comenzado esta historia, tenemos la oportunidad de conmemorar con ustedes los logros alcanzados, y celebrar el impacto que juntos hemos conseguido; pero a la vez, prepararnos para los retos que plantea el futuro. Nuestra memoria histórica está repleta de gran cantidad de nombres, rostros y miradas; así como de talento, creatividad y compromiso.

Los alcances que tiene la SMP no pudieron lograrse sin el cobijo de hospitales, medios de comunicación, industria farmacéutica, organismos sociales, y de otras agrupaciones médicas, las cuales han aportado desde el rol que les ha tocado desempeñar, lo mejor de sí mismos, aunado a su compromiso, trabajo y corazón.

\section{UNA SOCIEDAD EN EVOLUCIÓN CONSTANTE}

Durante la gestión 2019-2020, la SMP ha continuado ofreciendo cursos académicos que no sólo son indispensables para los pediatras en México, sino también para otros profesionales afines, donde se incluye personal de enfermería, médicos generales, médicos familiares, residentes y estudiantes de medicina. Así, en los últimos 14 meses, se han impartido 44 cursos presenciales, con 2,035 asistentes. En esta área, como en otras, la variedad de temas y la alta calidad de los profesores invitados son una referencia para la Pediatría mexicana.

A fin de incorporar las nuevas tecnologías de comunicación y educación, en el último trimestre del 2019 empezamos a realizar pruebas para transmitir sesiones académicas virtuales. Con esto se agregaron otros valores para nuestra organización, como son la modernidad e innovación.

Por fortuna, la inversión en la incorporación de esta tecnología, a partir de marzo de 2020, nos permitió trabajar por completo bajo esta nueva modalidad de educación a distancia al 100\%, por el efecto que ha tenido la pandemia originada por el virus SARS-CoV-2.

\footnotetext{
+ Correspondencia: CGB, dr.garciabolanos64@gmail.com

Conflicto de intereses: El autor declara que no tiene.

Citar como: García-Bolaños C. Nonagésimo aniversario de la Sociedad Mexicana de Pediatría: 1930-2020. Rev Mex Pediatr. 2020; 87(6); 203-206. https://dx.doi.org/10.35366/97680
} 
Con esta base, podemos reafirmar que en la presente gestión (al igual que las que la antecedieron) se ha buscado el crecimiento constante, con el propósito de mantener el liderazgo a nivel nacional que ha tenido desde su fundación, ocupando el primer lugar en la educación médica continua del Pediatra. Este crecimiento siempre ha sido posible a través de la planeación adecuada, a fin de garantizar su sustentabilidad para mantener la confianza de sus socios.

\section{CONSEJO ADMINISTRATIVO}

Creado en el año 2018, de acuerdo con el artículo 25 de los estatutos de la SMP, está integrado por el presidente y vicepresidente en turno, el presidente inmediato anterior y un comisario. Sus funciones están señaladas en el mismo artículo:

a) Deberá sesionar al menos cuatro veces al año, y es responsable de vigilar los acuerdos tomados por la mesa directiva de la sociedad.

b) Formalizar acuerdos administrativos o financieros, con impacto de largo plazo.

c) Compra y venta de bienes inmuebles.

d) Designación y revocación de los nombramientos.

e) Aprobación de estados financieros.

f) Designar o ratificar al director del Centro de Adiestramiento en Reanimación Pediátrica, al director-editor de la Revista Mexicana de Pediatría, así como al director de la página de Internet, cada dos años.

Este consejo constituye un órgano fundamental para que la SMP realice un trabajo totalmente transparente, y que se garantice, no solamente el buen uso de los recursos económicos ante sus socios sino que dé continuidad a los programas totales de la Sociedad a lo largo de los años.

\section{ALIANZAS Y CONVENIOS}

También en el periodo 2019-2020 se firmó un convenio específico de colaboración con la Academia Mexicana de Pediatría a través de su presidente actual, el Dr. Roberto Calva Rodríguez, en el cual se otorgó un espacio en la Revista Mexicana de Pediatría para publicar sus artículos, pero bajo los lineamientos de la propia revista.

Además, firmamos convenios con la Asociación Española de Pediatría, a través de su presidenta, la Dra. María José Mellado Peña, y con la Sociedad Argentina de Pediatría, con su presidente, el Dr. Omar L. Tabacco para tener intercambios académicos constantes, así como la participación de profesores de ambas agrupaciones en eventos, de manera recíproca.

\section{LAS CINCO DIVISIONES DE LA SOCIEDAD}

En la actualidad, la SMP tiene seis áreas de trabajo específicas: plataforma digital de educación médica continua, dirección editorial (Revista Mexicana de Pediatría, intranet, página web, centro de reanimación y el Comité de Ética.

I. Plataforma digital de educación médica continua. En esta plataforma se pueden encontrar cursos en línea, cápsulas informativas por profesores expertos en diferentes áreas, casos clínicos, artículos de interés, revisiones bibliográficas con temas de actualidad y sesiones grabadas del programa académico. De esta manera, se tiene la oportunidad de consultar cuantas veces se requiera, desde cualquier parte del mundo y en el momento que mejor se ajuste a su agenda. Por supuesto, toda esta información es un beneficio y cuenta con precios preferenciales para nuestros socios.

Hasta el momento, tenemos disponibles 10 cursos y 129 conferencias; además, hemos registrado 3,219 usuarios, de los cuales 1,388 son recurrentes. Si bien, la mayoría son mexicanos, tenemos usuarios de Bolivia, Chile, Colombia, Ecuador, EUA, Perú y Venezuela.

II. Dirección editorial. Desde la fundación de la Sociedad, la Revista Mexicana de Pediatría ha sido uno de sus pilares y no ha dejado de publicarse. En la presente gestión se logró digitalizar el total de los números publicados de manera impresa, desde el primer volumen, en 1930, hasta 1994. Con esto no solamente se garantiza la salvaguarda de tan valioso material que narra el desarrollo de la historia de la Pediatría en nuestro país, sino que el total de los números publicados ya puede ser consultado en cualquier parte del mundo, recordando que a partir de 1994 la revista dispone de una versión electrónica, disponible para todos de manera gratuita.

III. Intranet. Se trata de una plataforma digital que funciona las 24 horas y los siete días de la semana, en la cual se pueden tramitar nuevas afiliaciones y reingresos, realizar pagos en línea a cursos, congresos, talleres y anualidades. También se puede consultar y descargar constancias de los diferentes cursos realizados. 
De esta forma, la SMP reafirma su compromiso con el cuidado del medioambiente, debido a que se elimina el uso de papel para la impresión de constancias, documentos y expedientes de los socios.

IV. Página web. La página principal de Internet de nuestra organización se modernizó en el 2019, a fin de hacerla ágil, vistosa y amigable al usuario. Ahora se puede acceder fácilmente al programa académico anual, mantener informados a los usuarios y contactar fácilmente con nuestro personal.

A raíz del cierre de oficinas debido a la pandemia de Covid-19, la SMP respondió rápidamente y, en sólo seis meses, se impartieron 24 sesiones de manera virtual con 80 profesores, a las cuales asistieron 6,140 personas. Lo anterior muestra que se puede incrementar el número de personas para su capacitación, a pesar de no dar cursos presenciales.

Un logro a destacar fue la realización, por primera vez, de la votación a distancia para elegir a los nuevos miembros de la Mesa Directiva de la SMP para la gestión 2021-2022, a través de la plataforma Zoom, así como modificación de cuatro estatutos de la Sociedad.

V. Centro de Reanimación. Está compuesto por el Centro de Reanimación Cardiopulmonar (CARP) y el Centro de Reanimación Neonatal. En el primero se imparten cursos por los mejores instructores en el tema, que ofrecen un sello de garantía, con un nivel de excelencia, basado en 18 años de experiencia en impartir reanimación cardiopulmonar pediátrica avanzada (PALS) y reanimación cardiopulmonar básica (BLS). Ambos reúnen las características de tradición, innovación y aplicabilidad, típicas de los eventos organizados por la SMP. Contamos actualmente con seis sitios de cursos de reanimación pediátrica a lo largo de todo el país, con alta capacitación y profesionalismo, bajo los estándares internacionales dictados por la American Heart Asociation.

En el presente bienio, se capacitó a 1,299 proveedores en BLS; 1,130 en PALS y 15 en valoración, reconocimiento y estabilización de emergencias pediátricas (PEARS). En lo que respecta a los cursos dirigidos a la población civil (conocidos como legos) se capacitaron 22 personas en el curso de Salva Corazones; 39 de familiares y amigos, Hands Only 394 asistentes y 20 para el CPR Any Time. Asimismo, en este periodo se formaron 25 nuevos instructores en cada disciplina de BLS y PALS.

Centro de Reanimación Neonatal. Cursos que cumplen con altos estándares, con fundamento en las más recientes actualizaciones de las guías internacionales sobre el tema. Durante 2020 se impartieron 16 cursos con 130 alumnos, y un curso de instructores con 15 alumnos.

VI. Comité de Bioética. Este Comité cumple cuatro años desde que inició. Está constituido por eminentes bioeticistas, quienes son académicos expertos en la bioética o pediatría. Lo dirige el Dr. Remigio Antonio Véliz Pintos, y está integrado por la Dra. Ma. Cristina Caballero Velarde, Dr. Armando Garduño Espinosa, Dra. María de la Luz L. Casas Martínez y la Dra. Martha Tarasco Michel.

En el transcurso de estos años se han desarrollado dos seminarios y más de 30 simposios de bioética en Pediatría. Además, se realizó un Congreso Nacional de Bioética, y se escribieron dos libros de "Bioética y Humanismo para Pediatría".

Este Comité aconseja que el acto clínico no puede ni debe separarse del acto bioético.

\section{COMENTARIOS FINALES}

Este 90 aniversario de la SMP se cumple en medio de un momento muy triste para el mundo y para México, por lo devastadora que ha resultado la pandemia por Covid-19, tanto para la salud como para la economía. Al momento de escribir este texto, se habían contabilizado 97,056 mexicanos muertos y 991,835 casos confirmados.

A pesar de lo anterior, estoy convencido de que la SMP debe seguir trabajando para generar cambios positivos en la Pediatría mexicana. Estos cambios se deben, en parte, a que en los últimos cuatro años se han desarrollado planes de largo plazo (como la digitalización de los servicios, acuerdos internacionales, y posición financiera sólida) para que la SMP pueda recuperar su primera posición dentro del gremio de pediatras.

Como parte de la planeación a largo plazo, en los estatutos actuales se deja en claro que los candidatos a ocupar cargos en la mesa directiva deben haber realizado previamente trabajo a favor de la Sociedad, con el propósito de continuar sus programas y objetivos. Estos candidatos habrán de exponer su plan de trabajo y curriculum vitae, para que los socios oportunamente conozcan por quién votarán.

La presidencia de la SMP ofrece un gran orgullo para quien le corresponde ejercerla, pero también es una gran responsabilidad. Por supuesto, el presidente debe dar continuidad a los programas exitosos, 
al mismo tiempo que diseña nuevas actividades que permitan la expansión de la Sociedad. Sin embargo, su trabajo no es sencillo, ya que es blanco del escrutinio, críticas e incluso de golpes bajos y fuego amigo. A pesar de lo anterior, el presidente debe mostrar su lealtad a la SMP, sin permitir injerencias externas.

Por último, además de reconocer a la Mesa Directiva y grupo secretarial que me acompañó, quiero expresar, estimados socios, que ha sido un honor haberles servido a todos ustedes durante este periodo 2019-2020. Y, aunque las circunstancias de restricción debido a la pandemia no permitieron concretar otros planes, la experiencia en la presidencia de la SMP ha resultado de lo más nutritiva para mi vida.

Hoy más que nunca refrendemos el cumplimiento de nuestro lema:

¡Amor y ciencia al servicio de la niñez! 